\title{
The clinical value of three-dimensional measurement in the diagnosis of thoracic myelopathy caused by ossification of the ligamentum flavum
}

\author{
Chen Yan ${ }^{1,2 \#}$, Hao-Yuan Tan ${ }^{1,2 \#}$, Cheng-Long Ji ${ }^{1 \#}$, Xue-Wei Yu ${ }^{1,2}$, Huai-Cheng Jia ${ }^{1,2}$, Fu-Dong Li ${ }^{1}$, \\ Gui-Cheng Jiang ${ }^{1}$, Wei-Shi Li ${ }^{3}$, Fei-Fei Zhou ${ }^{3}$, Zhen Ye ${ }^{4}$, Jing-Chuan Sun ${ }^{1}$, Jian-Gang Shi ${ }^{1}$ \\ ${ }^{1}$ Second Department of Spine Surgery, Changzheng Hospital, Second Military Medical University, Shanghai, China; ${ }^{2}$ Undergraduate Incubation \\ Center, Second Military Medical University, Shanghai, China; ${ }^{3}$ Department of Orthopaedics, Peking University Third Hospital, Beijing, China; \\ ${ }^{4}$ Shanghai Electric Group Limited Liability Company Central Academe, Shanghai, China \\ "These authors contributed equally to this work. \\ Correspondence to: Jing-Chuan Sun, MD; Jian-Gang Shi, MD. Second Department of Spine Surgery, Changzheng Hospital, Second Military Medical \\ University, No. 415, Fengyang Road, Shanghai 200001, China. Email: theway1828@163.com; changzhengspine@smmu.edu.cn.
}

Background: Thoracic ossification of the ligamentum flavum (OLF) is a major cause of thoracic myelopathy, which is often accompanied by multiple segmental stenosis or other degenerative spinal diseases. However, in the above situations, it is difficult to determine the exact segment responsible. The objective of this study was to analyze three-dimensional (3D) radiological parameters in order to establish a novel diagnostic method for discriminating the responsible segment in OLF-induced thoracic myelopathy, and to evaluate its superiority compared to the conventional diagnostic methods.

Methods: Eighty-one patients who underwent surgery for thoracic myelopathy caused by OLF from 2016 to 2020 were enrolled in this study as the myelopathy group, and 79 patients who had thoracic OLF but displayed no definite neurological signs from 2018 to 2020 were enrolled as the non-myelopathy group. We measured the one-dimensional (1D), two-dimensional (2D), and 3D radiological parameters, calculated their optimal cutoff values, and compared their diagnostic values.

Results: Significant differences were observed in the 1D, 2D, and 3D radiological parameters between the myelopathy and non-myelopathy groups $(\mathrm{P}<0.01)$. As a 3D radiological parameter, the OLF volume $(\mathrm{OLFV})$ ratio $(\mathrm{OLFV}$ ratio $=\mathrm{OLFV} /$ normal canal volume $\times 100 \%)$ was the most accurate parameter for diagnosing OLF-induced thoracic myelopathy, with a diagnostic coincidence rate of $88.1 \%$. We also found that an OLFV ratio of $26.3 \%$ could be used as the optimal cutoff value, with a sensitivity of $87.7 \%$ and a specificity of $88.6 \%$. Moreover, the OLFV ratio [area under the curve (AUC): $0.92,95 \%$ confidence interval (CI): 0.86-0.95] showed a statistically higher diagnostic value than the $1 \mathrm{D}$ and 2D parameters (AUC: 0.75, 95\% CI: 0.67-0.81; AUC: 0.84, 95\% CI: 0.77-0.89, respectively) $(\mathrm{P}<0.05)$. Pearson correlation analysis illustrated that the OLFV ratio was significantly negatively correlated with preoperative modified Japanese Orthopedic Association (mJOA) score ( $\mathrm{r}=-0.73,95 \% \mathrm{CI}$ : -0.81 to $-0.60, \mathrm{P}<0.01)$.

Conclusions: Our results demonstrate the superiority of the OLFV ratio over the conventional $1 \mathrm{D}$ and 2D computed tomography (CT)-based radiological parameters for the diagnosis of OLF-induced thoracic myelopathy. The novel diagnostic method based on the OLFV ratio will help to determine the responsible segment in multi-segmental thoracic OLF or when thoracic OLF coexists with other degenerative spinal diseases. The OLFV ratio also accurately reflects the clinical state of symptomatic patients with thoracic OLF.

Keywords: Ossification of the ligamentum flavum (OLF); three-dimensional image (3D image); thoracic myelopathy; diagnostic imaging; computed tomography (CT) 
Submitted May 29, 2020. Accepted for publication Jan 27, 2021.

doi: 10.21037/qims-20-713

View this article at: http://dx.doi.org/10.21037/qims-20-713

\section{Introduction}

Thoracic ossification of the ligamentum flavum (OLF) is characterized by pathological calcification and growth of the ligamentum flavum, and is increasingly recognized as a major cause of thoracic myelopathy $(1,2)$. Other accompanying degenerative spinal diseases and multiple segmental stenosis are the two frequently observed features of thoracic OLF (3-6). Additionally, the complex relationship between the thoracic spinal canal and the spinal cord may result in multiple clinical manifestations (4). In the above situations, it is often difficult to determine the exact segment responsible for thoracic myelopathy. These diagnostic problems may affect surgical planning and clinical outcomes. Hence, it is necessary to establish an accurate diagnostic method to address the problems in identifying the responsible segment in thoracic myelopathy caused by OLF.

Previous reports have identified valuable radiological parameters, such as a canal grade (paramedian) (CGP) and an OLF area (OLFA) ratio, for the diagnosis of OLFinduced thoracic myelopathy based on one-dimensional (1D) or two-dimensional (2D) measurement methods $(5,6)$. However, these conventional radiological parameters may not provide sufficient information to determine the responsible segment, because thoracic OLF is a three-dimensional (3D) disease, as opposed to a $1 \mathrm{D}$ or 2D disease (7). Recent studies have displayed a new technique to measure the ossification volume based on $3 \mathrm{D}$ reconstruction from computed tomography (CT) images (7-9). In this study, we sought to analyze 3D radiological parameters in order to establish a novel diagnostic method for discriminating the responsible segment in OLFinduced thoracic myelopathy, and to evaluate its superiority compared to the conventional diagnostic methods.

\section{Methods}

\section{Patient population}

We retrospectively analyzed 254 consecutive patients who underwent decompressive laminectomy for the treatment of thoracic OLF from January 2016 to January 2020 at Changzheng Hospital. The following exclusion criteria were set in order to only include patients with thoracic myelopathy caused by OLF: (I) patients with a history of spinal tumor, deformity, or surgery; (II) patients with accompanying compressive lesions in other spinal regions, such as cervical ossification of the posterior longitudinal ligament (OPLL) or thoracic disk herniation; (III) patients with other accompanying spinal diseases requiring operative treatment; (IV) patients with accompanying neurological diseases such as Parkinson's disease and stroke; and (V) patients with incomplete data. After filtering patients using these criteria, 173 patients were excluded and 81 were finally enrolled as the myelopathy group (Figure 1). Neurological function was assessed on the basis of a modified Japanese Orthopedic Association (mJOA) scoring system for thoracic myelopathy (Table 1) (8).

Meanwhile, 348 consecutive patients who were hospitalized for thoracic or lumbar compressive fractures from March 2018 to January 2020 were also retrospectively analyzed. The following inclusion criteria were set in order to include negative control patients: (I) patients with thoracic OLF based on imaging examinations; and (II) patients with no definite neurological signs (mJOA scores $=11$ ). After filtering patients according to these criteria, 79 patients were finally enrolled as the nonmyelopathy group (Figure 1). The clinical characteristics of the included patients were recorded, including sex, age, and comorbidities [diabetes mellitus (DM) and hypertension (HTN)]. This study was approved by Medical Ethics Committee of Shanghai Changzheng Hospital, and informed consent was obtained from all patients.

\section{Radiological assessment and measurement}

The preoperative magnetic resonance imaging (MRI) and CT images of all patients were collected, and CT data were saved as Digital Imaging and Communications in Medicine (DICOM) files. All radiological data were independently assessed by two experienced observers, who were blinded to the group situation and patient information. Each observer measured all of the radiological parameters three times and recorded the mean values. Interclass correlation coefficients were calculated to assess the intra-observer reproducibility and inter-observer reliability. 


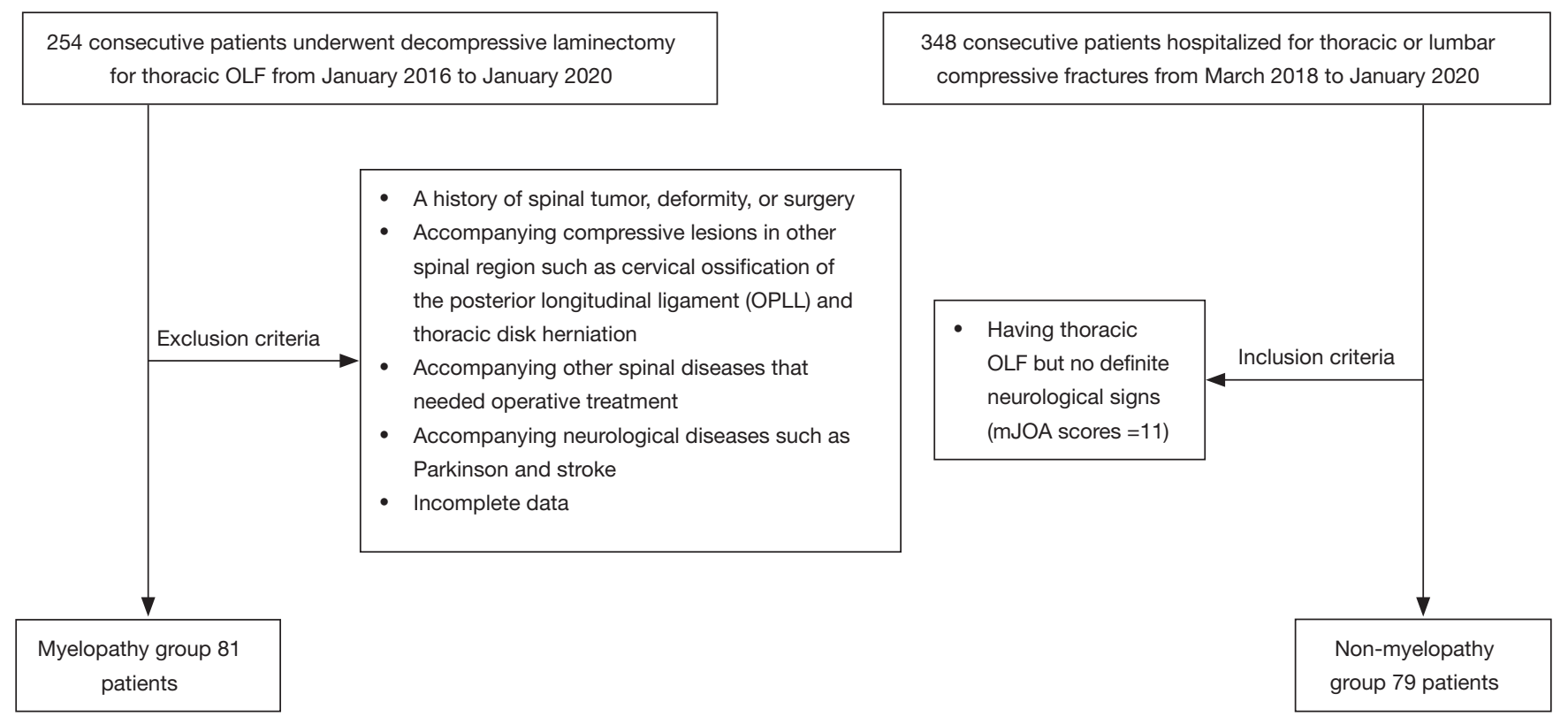

Figure 1 Patient screening and classification flowchart. OLF, ossification of the ligamentum flavum; mJOA, modified Japanese Orthopedic Association.

Table 1 mJOA scoring system for the assessment of thoracic myelopathy

\begin{tabular}{|c|c|}
\hline Categories & $\begin{array}{l}\text { Score } \\
\text { (points) }\end{array}$ \\
\hline \multicolumn{2}{|l|}{ Motor function: lower extremity } \\
\hline Impossible to walk & 0 \\
\hline Need a cane or aid on flat ground & 1 \\
\hline Need aid only on stairs & 2 \\
\hline Possible to walk without any aid, but slow manner & 3 \\
\hline Normal & 4 \\
\hline \multicolumn{2}{|l|}{ Sensory function: lower extremity } \\
\hline Apparent sensory disturbance & 0 \\
\hline Minimal sensory disturbance & 1 \\
\hline Normal & 2 \\
\hline \multicolumn{2}{|l|}{ Sensory function: trunk } \\
\hline Apparent sensory disturbance & 0 \\
\hline Minimal sensory disturbance & 1 \\
\hline Normal & 2 \\
\hline \multicolumn{2}{|l|}{ Bladder function } \\
\hline Urinary retention or incontinence & 0 \\
\hline Severe dysuria (sense of retention, staining) & 1 \\
\hline Slight dysuria (pollakisuria, retardation) & 2 \\
\hline Normal & 3 \\
\hline Total score & 11 \\
\hline
\end{tabular}

mJOA, modified Japanese Orthopedic Association.
According to the thoracic spine level, thoracic OLF was classified as upper (T1-T4), middle (T5-T8), and lower (T9-T12). The extent of OLF was defined as the number of levels involved in the thoracic OLF. The presence of high intramedullary signal on T2-weighted MRI (T2HIS) was also recorded.

The $1 \mathrm{D}$ and $2 \mathrm{D}$ radiological parameters, including the anteroposterior canal diameter (APD), CGP, OLFA, and OLFA ratio, were measured using the IMPAX 6.0 software (AGFA, Inc., Belgium). The 3D radiological parameters, including the OLF volume (OLFV) and OLFV ratio, were measured using Mimics software 19.0 (Materialise, Inc., Belgium). Previous studies reported that, among these radiological parameters, the CGP and OLFA ratio were, respectively, the most accurate $1 \mathrm{D}$ and $2 \mathrm{D}$ diagnostic indicators of OLF-induced thoracic myelopathy $(5,6)$.

\section{APD and CGP}

According to the 1D measurement method described by Feng et al., the APD was defined as the spinal canal diameter between the midline and boundary of the canal at the maximally stenosed level on axial CT (Figure 2) (5). The normal canal diameter was defined as the average spinal canal diameter of the adjacent non-stenosed segments with no ossification and the widest distance between the pedicles. The CGP was calculated was follows: 

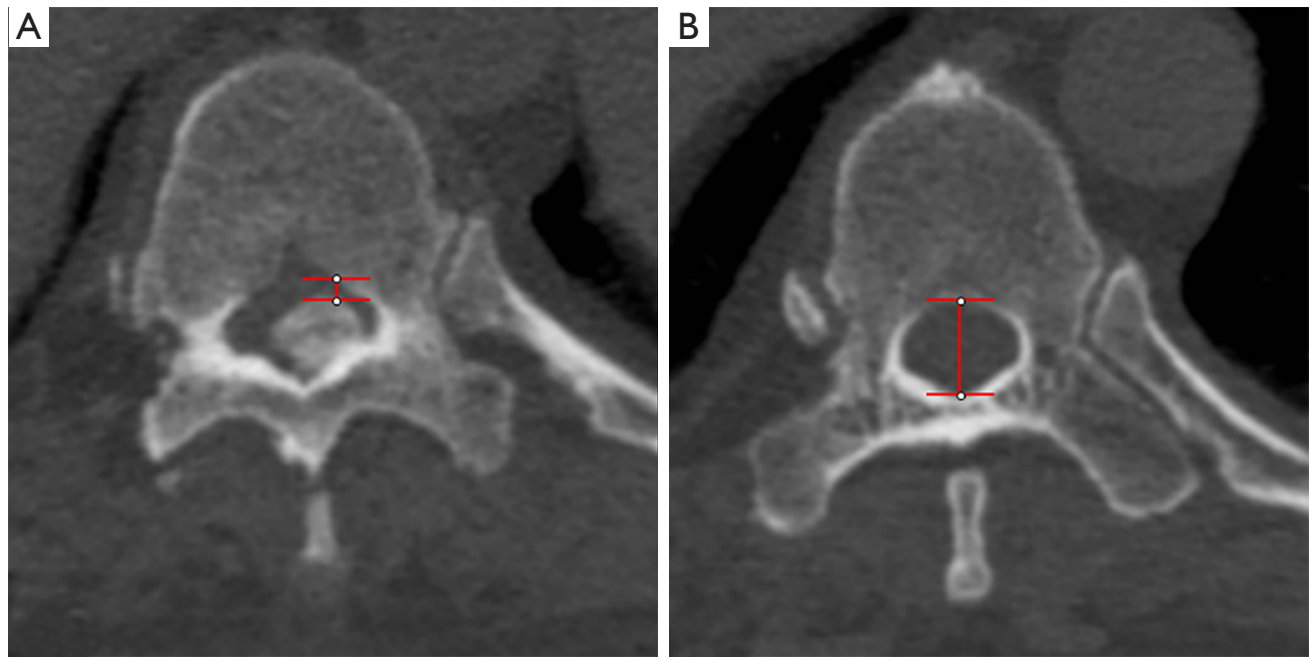

Figure 2 Measurement of the APD (A) and normal canal diameter (B). APD, anteroposterior canal diameter.
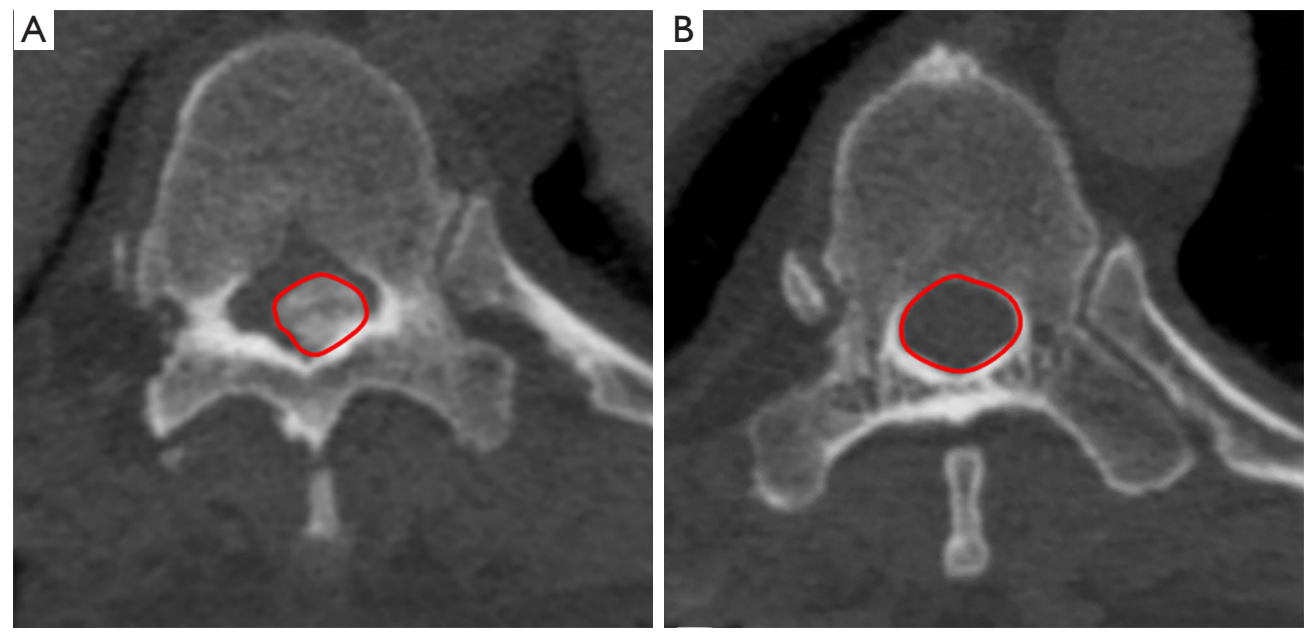

Figure 3 Measurement of the OLFA (A) and normal canal area (B). OLF, ossification of the ligamentum flavum; OLFA, OLF area.

$$
C G P=A P D / \text { normal canal diameter } \times 100 \%
$$

\section{OLFA and OLFA ratio}

According to the 2D measurement method described by Lee et al., the OLFA was defined as the cross-sectional area of the OLF at the thickest point on axial CT (Figure 3) (6). The normal canal area was defined as the average spinal canal area of the adjacent non-stenosed segments with no ossification and the widest distance between the pedicles. The OLFA ratio was calculated as follows:

$$
\text { OLFA ratio }=O L F A / \text { normal canal area } \times 100 \%
$$

\section{OLFV and OLFV ratio}

The DICOM files of preoperative CT images were imported into MIMICS software using the non-strict DICOM 3.0 method. There are four steps of operating procedures of $3 \mathrm{D}$ measurement on the Mimics software (Figure 4) As an example, the steps for measurement of OLFV are as follows: (I) segmentation of the spine and creation of a mask by setting a threshold value of bone [226-1,751 Hounsfield units (HU)]; (II) further selection of the required region of the mask from sagittal, coronal, and axial dimensions to identify the structure of the OLF by 

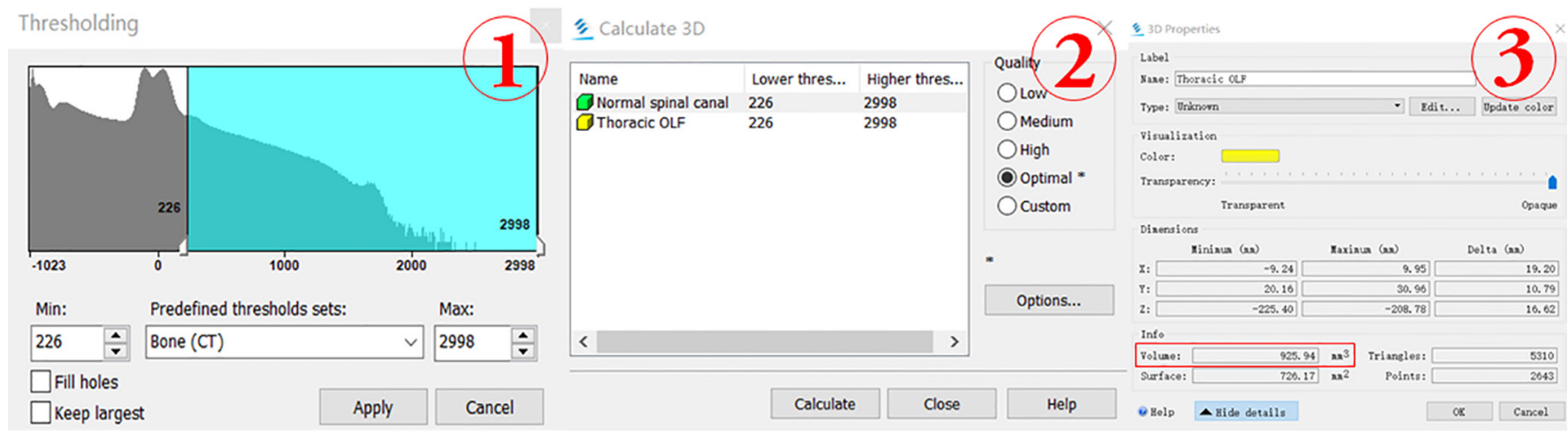

Figure 4 The operating procedures of 3D measurement on Mimics software. Step 1: setting a threshold value. Step 2: selection of the required region. Step 3: model reconstruction. Step 4: volume measurement. 3D, three-dimensional.
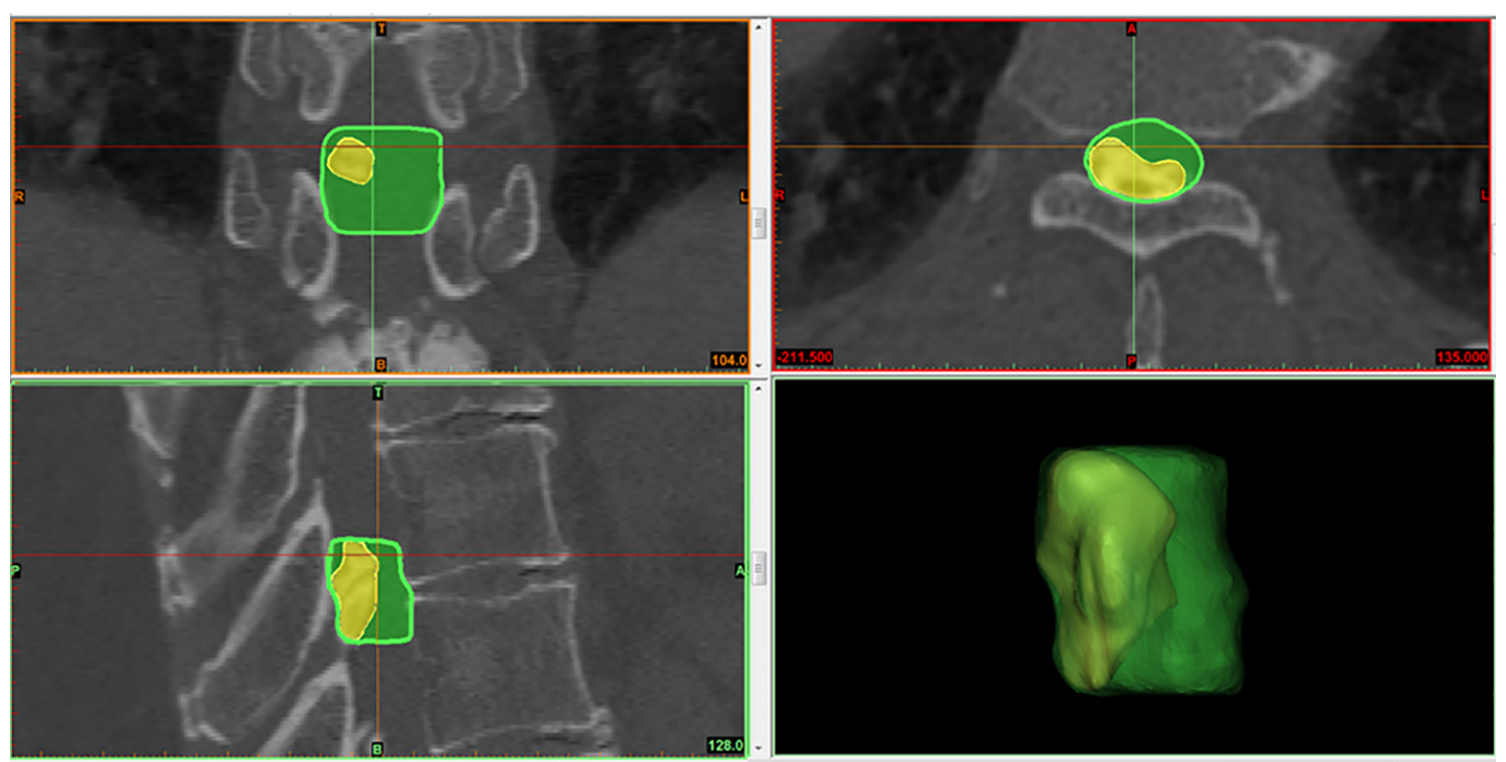

Figure 5 Measurement of the OLFV (green) and normal canal volume (yellow). OLF, ossification of the ligamentum flavum; OLFV, OLF volume.

pressing the Crop mask button; (III) reconstruction of the 3D model of thoracic OLF based on the mask by pressing the Calculate 3D button; and (IV) automatic measurement of the volume of the thoracic OLF by pressing the 3D Properties button. The OLFV was defined as the volume of the OLF at the maximally stenosed level (Figure 5). The normal canal volume was defined as the volume of the spinal canal corresponding to the measured OLF (the top and bottom of the normal spinal canal were consistent with the top and bottom of the measured OLF). The OLFV ratio was calculated as follows:
$O L F A$ ratio $=O L F A /$ normal canal volume $\times 100 \%$

\section{Statistical analysis}

All analyses were performed using MedCalc 19.0 (MedCalc Software Ltd., Inc., Belgium) and SPSS Statistics 20.0 (SPSS, Inc., Chicago, IL, USA). Continuous variables were reported as mean \pm standard deviation $(\mathrm{SD})$, and categorical variables were reported as frequencies. Comparison of the clinical and radiological parameters between the myelopathy group and non-myelopathy group was conducted through 
Table 2 Comparison of the clinical and radiological parameters between the myelopathy group and non-myelopathy group

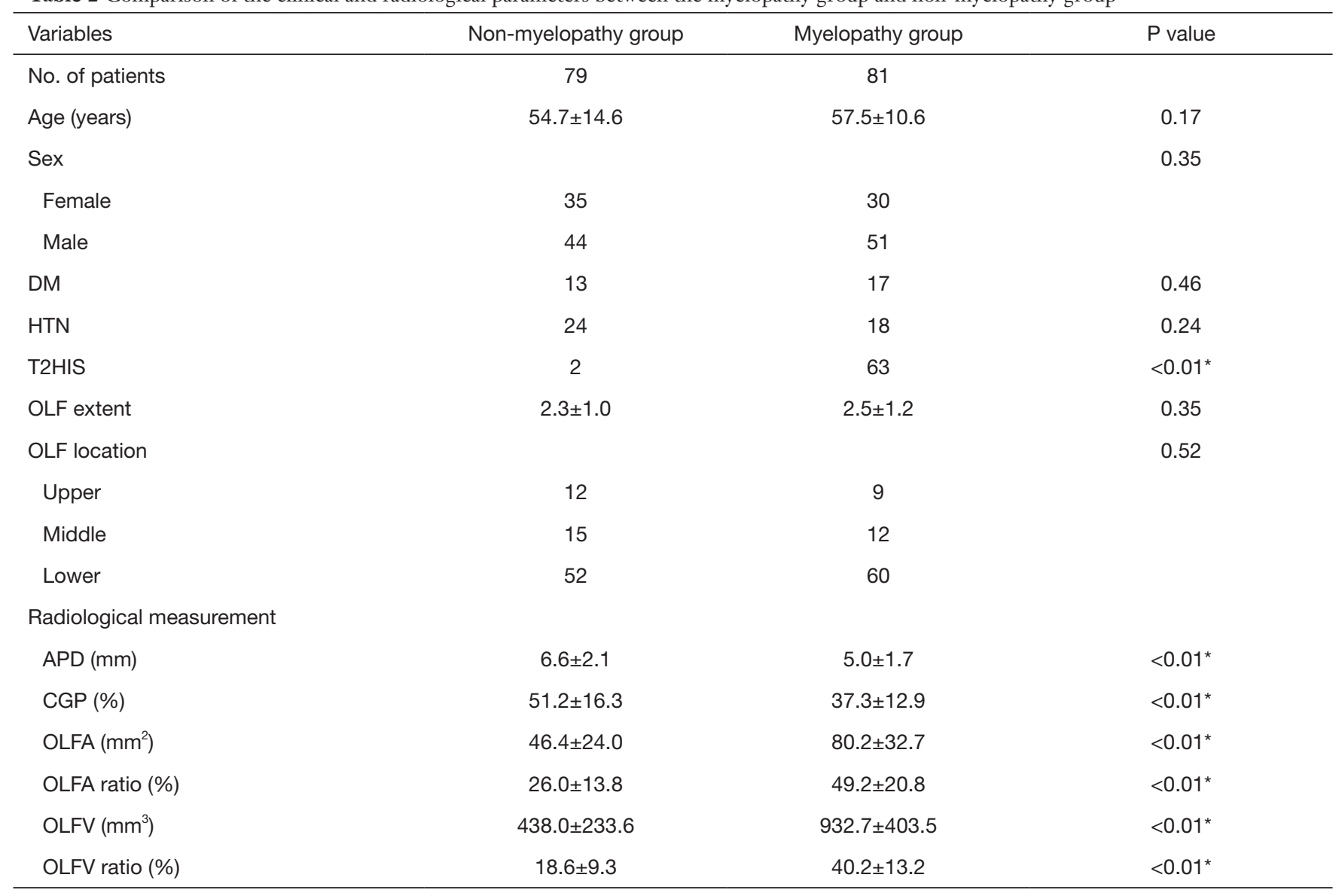

*, statistically significant. DM, diabetes mellitus; HTN, hypertension; T2HIS, high intramedullary signal on T2-weighted MRI; OLF, ossification of the ligamentum flavum; APD, anteroposterior canal diameter; CGP, canal grade (paramedian); OLFA, OLF area; OLFV, OLF volume.

the performance of independent $t$-tests for continuous variables and chi-square tests for categorical variables. The optimal cutoff values of the 1D, 2D, and 3D radiological parameters for diagnosing OLF-induced thoracic myelopathy were calculated by receiver operating characteristic (ROC) curve analysis. $Z$-tests were used to compare the diagnostic values of the $1 \mathrm{D}, 2 \mathrm{D}$, and $3 \mathrm{D}$ radiological parameters based on the areas under the ROC curves (AUCs). The association between the radiological parameters for thoracic myelopathy and the preoperative neurological status (mJOA score) was investigated using Pearson's correlation analysis. A P value $<0.05$ was considered to be statistically significant.

\section{Results}

\section{Patient characteristics}

As shown in Table 2, no significant variations in age $(\mathrm{P}=0.17)$, sex $(\mathrm{P}=0.35)$, comorbidities $(\mathrm{P}=0.24, \mathrm{P}=0.46)$, or the extent $(\mathrm{P}=0.35)$ or location $(\mathrm{P}=0.52)$ of $\mathrm{OLF}$ were observed between the myelopathy group and the non-myelopathy group. In the myelopathy group, 63 patients had T2HIS, compared with only two patients in the non-myelopathy group, which represented a statistically significant difference $(\mathrm{P}<0.01)$.

\section{Radiological parameters}

The intra- and inter-observer correlation coefficients were 0.90 and 0.87 , respectively, which showed strong agreement among the measurements. With respect to $1 \mathrm{D}$ radiological parameters, in the myelopathy and non-myelopathy groups, the mean APD was $5.0 \pm 1.7$ and $6.6 \pm 2.1 \mathrm{~mm}$, respectively, and the mean CGP was $37.3 \% \pm 12.9 \%$ and $51.2 \% \pm 16.3 \%$, respectively. With respect to $2 \mathrm{D}$ radiological parameters, 

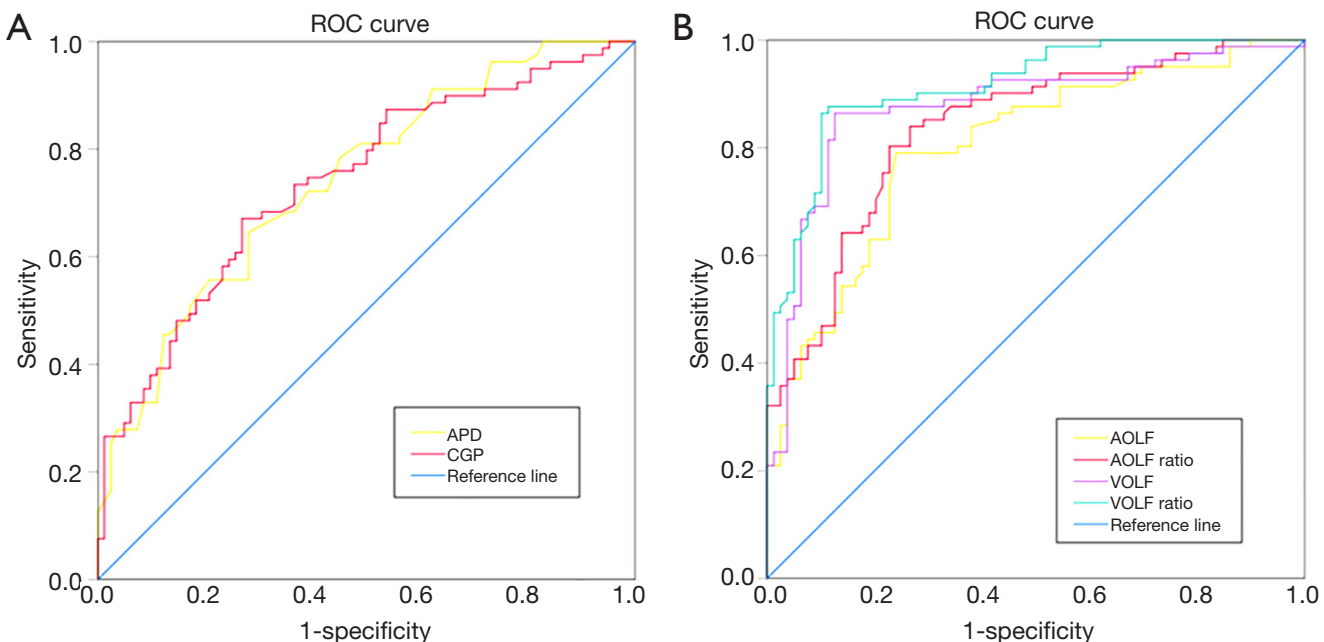

Figure 6 ROC curves of the 1D, 2D, and 3D radiological parameters. ROC, receiver operating characteristic; 1D, one-dimensional; 2D, two-dimensional; 3D, three-dimensional; APD, anteroposterior canal diameter; CGP, canal grade (paramedian); OLF, ossification of the ligamentum flavum; OLFA, OLF area; OLFV, OLF volume.

in the myelopathy and non-myelopathy groups, the mean OLFA was $80.2 \pm 32.7$ and $46.4 \pm 24.0 \mathrm{~mm}^{2}$, respectively, and the mean OLFA ratio was $49.2 \% \pm 20.8 \%$ and $26.0 \% \pm 13.8 \%$, respectively. With respect to $3 \mathrm{D}$ radiological parameters, in the myelopathy and non-myelopathy groups, the mean OLFV was $932.7 \pm 403.5$ and $438.0 \pm 233.6 \mathrm{~mm}^{3}$, respectively, and the mean OLFV ratio was $40.2 \% \pm 13.2 \%$ and $18.6 \% \pm 9.3 \%$, respectively. Statistically significant differences existed in the $1 \mathrm{D}, 2 \mathrm{D}$, and $3 \mathrm{D}$ radiological parameters between the two groups $(\mathrm{P}<0.01)$.

\section{Diagnostic value}

The ROC curves of the $1 \mathrm{D}, 2 \mathrm{D}$, and $3 \mathrm{D}$ radiological parameters are illustrated in Figure 6. Among all of the measured parameters, the OLFV ratio was the most accurate parameter for the diagnosis of OLF-induced thoracic myelopathy, with a sensitivity of $87.7 \%$, a specificity of $88.6 \%$, and a diagnostic coincidence rate of $88.1 \%$ (Table 3). According to the maximum of the Youden index, the optimal cutoff value for the OLFV ratio was calculated at $26.3 \%$. Moreover, the OLFV ratio [AUC: 0.92, 95\% confidence interval (CI): 0.86-0.95] showed a statistically higher diagnostic value than both the 1D (CGP, AUC: $0.75,95 \%$ CI: $0.67-0.81$ ) and 2D (OLFA ratio, AUC: 0.84, 95\% CI: 0.77-0.89) radiological parameters $(\mathrm{P}<0.01$ and $\mathrm{P}=0.02$, respectively) (Table 4). Although the $2 \mathrm{D}$ radiological parameter (OLFA ratio) had a higher diagnostic coincidence rate than the $1 \mathrm{D}$ radiological parameter (CGP), the difference in diagnostic value between the two parameters was not statistically significant $(\mathrm{P}=0.10)$. Additionally, Pearson's correlation analysis revealed a significantly negative correlation between the OLFV ratio and preoperative neurological status $(\mathrm{r}=-0.73,95 \% \mathrm{CI}$ : -0.81 to $-0.60, \mathrm{P}<0.01)$. In Table 5, 81 patients with thoracic OLF are divided into three levels on the basis of mJOA scores for further analysis of the preoperative myelopathy severity and the OLFV ratio.

\section{Discussion}

Among individual patients with thoracic OLF, 40-60\% have lesions in multiple segments (10). However, not every affected segment will lead to thoracic myelopathy (6). Therefore, determining the segment responsible for spinal cord damage is challenging. Additionally, thoracic OLF often coexists with other degenerative spinal diseases, such as cervical OPLL and lumbar spinal stenosis $(11,12)$. Any of these diseases may cause lower-limb dysfunction. Thus, it is difficult to identify whether thoracic OLF is the main cause of neurological symptoms when these diseases coexist. Moreover, all of the aforementioned conditions might lead to errors at the surgical level, and ultimately, insufficient or excessive decompression.

It has been previously reported that electrophysiological examination might serve as a valuable method to 
Table 3 Cutoff values for the 1D, 2D, and 3D radiological parameters

\begin{tabular}{lcccc}
\hline Parameters & Cutoff & Sensitivity (\%) & Specificity (\%) & Diagnostic coincidence rate (\%) \\
\hline APD $(\mathrm{mm})$ & 6.0 & 72.8 & 64.6 & 69.4 \\
CGP (\%) & 45.6 & 74.1 & 67.1 & 70.0 \\
OLFA $\left(\mathrm{mm}^{2}\right)$ & 57.7 & 79.0 & 76.0 & 77.5 \\
OLFA ratio (\%) & 32.4 & 80.3 & 77.2 & 78.8 \\
OLFV $\left(\mathrm{mm}^{3}\right)$ & 599.0 & 86.4 & 87.3 & 86.7 \\
OLFV ratio (\%) & 26.3 & 87.7 & 88.6 & 88.1 \\
\hline
\end{tabular}

1D, one-dimensional; 2D, two-dimensional; 3D, three-dimensional; APD, anteroposterior canal diameter; CGP, canal grade (paramedian); OLF, ossification of the ligamentum flavum; OLFA, OLF area; OLFV, OLF volume.

Table 4 Comparison of the diagnostic value of the 1D, 2D, and 3D radiological parameters

\begin{tabular}{lccc}
\hline Parameters & AUC & $95 \% \mathrm{Cl}$ & P value \\
\hline CGP (\%) & 0.75 & $0.67-0.81$ & - \\
OLFA ratio (\%) & 0.84 & $0.77-0.89$ & - \\
OLFV ratio (\%) & 0.92 & $0.86-0.95$ & $<0.01^{*}$ \\
OLFV ratio vs. CGP & - & - & $0.02^{*}$ \\
OLFV ratio vs. OLFA ratio & - & - & 0.10 \\
OLFA ratio vs. CGP & - & - & - \\
\hline
\end{tabular}

*, statistically significant. 1D, one-dimensional; 2D, two-dimensional; 3D, three-dimensional; AUC, area under the receiver operating characteristic curve; Cl, confidence interval; CGP, canal grade (paramedian); OLF, ossification of the ligamentum flavum; OLFA, OLF area; OLFV, OLF volume; -, not available.

Table 5 Results of preoperative myelopathy severity and OLFV ratio analysis

\begin{tabular}{lccr}
\hline Preoperative myelopathy severity & No. of patients & mJOA score & OLFV ratio (\%) \\
\hline$\geq 8$ & 30 & $8.8 \pm 1.0$ & $30.4 \pm 9.0$ \\
$5-7$ & 41 & $6.1 \pm 1.0$ & $42.1 \pm 9.0$ \\
$\leq 4$ & 10 & $3.4 \pm 0.5$ & $62.3 \pm 8.3$ \\
P value & - & $<0.01^{*}$ & $<0.01^{*}$ \\
\hline
\end{tabular}

*, statistically significant. OLF, ossification of the ligamentum flavum; OLFV, OLF volume; mJOA, modified Japanese Orthopedic Association; -, not available.

determine the necessary surgical segment for thoracic myelopathy (13). However, it can be easily influenced by other factors, such as age and the use of anesthetics (14). Several studies have also reported that MRI is an important modality for determining the segment responsible for OLF-induced myelopathy. T2HIS can also be a good indicator of thoracic myelopathy (15). Nevertheless, in the present study, only $77 \%$ of patients with thoracic myelopathy demonstrated T2HIS. Moreover, in patients with continuous multi-segmental OLF, T2HIS extends over several segments, which will lead to diagnostic difficulty in determining the segment responsible (6). Feng et al. proposed a MRI grading system of spinal canal compromise for thoracic myelopathy; however, it is rather subjective. Furthermore, they found that MRI grading alone might not be very accurate for identifying the responsible segment, especially in cases with grade III compression (5). Additionally, Lee et al. adopted CT 
morphology classification for the diagnosis of thoracic myelopathy, but poor diagnostic accuracy was observed in the extended type (6).

Recently, several radiological parameters based on CT measurement were shown to possess increased accuracy as indicators for the diagnosis of OLF-induced thoracic myelopathy compared with the above-described diagnostic methods $(5,6)$. The CGP as a $1 \mathrm{D}$ radiological parameter was proposed as a critical diagnostic indicator for thoracic myelopathy, and the OLFA ratio as a $2 \mathrm{D}$ radiological parameter was later proposed. The OLFA ratio showed higher sensitivity and specificity than the CGP in diagnosing OLF-induced thoracic myelopathy, as it better reflected bilateral compression of OLF (according to Lee et al.). However, it is inadequate to evaluate the diagnostic value of these parameters for thoracic myelopathy based only on sensitivity or specificity as opposed to a statistical comparison $(16,17)$.

To the best of our knowledge, this study is the first to compare the diagnostic value of thoracic myelopathy among 1D, 2D, and 3D CT-based radiological parameters. As our results demonstrate, the CGP and OLFA ratio were the most accurate $1 \mathrm{D}$ and $2 \mathrm{D}$ radiological parameters, respectively, which is consistent with findings of previous studies $(5,6)$. Although the OLFA ratio had a higher diagnostic coincidence rate than the CGP, there was no statistically significant difference in the diagnostic values of the two parameters. Furthermore, we also found that the OLFV ratio showed a statistically higher diagnostic value in comparison with the $1 \mathrm{D}$ and $2 \mathrm{D}$ parameters. There are three factors that might have contributed to this result. Firstly, OLF is a $3 \mathrm{D}$ disease rather than a $1 \mathrm{D}$ or $2 \mathrm{D}$ disease. Previous studies have reported a series of radiological parameters that were associated with the diagnosis of thoracic myelopathy, including sagittal, coronal, and axial dimensions $(5,6,18,19)$, which highlighted the insufficiency of diagnosing thoracic myelopathy from only a single dimension. Conversely, compared to the above radiological parameters, the $3 \mathrm{D}$ radiological parameters can evaluate OLF compression more comprehensively from multiple dimensions (20). Secondly, it might not be suitable to evaluate the severity of OLF compression using the 1D or $2 \mathrm{D}$ radiological parameters in the upper and middle thoracic spine. Considering that patients usually undergo CT examination in the supine position, the axial plane of CT scanning and the transverse plane of the upper or middle thoracic spinal canal are at an angle to each other, which will result in larger errors in the results of $1 \mathrm{D}$ or $2 \mathrm{D}$ measurement (21). However, the 3D measurement method can avoid this problem, since the same $3 \mathrm{D}$ model will be reconstructed at any angle of CT scanning (22). Thirdly, the automatic measurement of $3 \mathrm{D}$ parameters using Mimics software can minimize human error resulting from manual measurement (7). Therefore, better inter- and intraobserver reliability are obtained with the $3 \mathrm{D}$ measurement method than with the 1D or 2D measurement method (23).

Previous studies have demonstrated that the $3 \mathrm{D}$ radiological parameter is associated with the clinical state of symptomatic patients with other ossification diseases $(7,24)$. Therefore, we also investigated the relationship between the OLFV ratio and the preoperative neurological status of patients with thoracic OLF. The OLFV ratio showed a significant negative correlation with patients' preoperative mJOA scores $(r=-0.73, \mathrm{P}<0.01)$, suggesting that the OLFV ratio accurately reflected the clinical state of symptomatic patients with thoracic OLF.

The current study has several limitations that should be noted. Firstly, the sample size is relatively small due to the low incidence of thoracic OLF. Moreover, it is a single-center and retrospective study. Therefore, a larger, multicenter, prospective study is needed to verify our results in the future. Additionally, the impact of two potential factors on neurological function was not evaluated in this article. The first factor is diffuse idiopathic skeletal hyperostosis (DISH). Our screening criteria did not involve this point; although, the prevalence of the coexistence of DISH and OLF is relatively low (25-27). Secondly, the impact of the location or extent of kyphosis on neurological function was also not analyzed in this study due to the limited number of patients (28). Lastly, the 3D reconstruction technique based on the Mimics software has been applied to various clinical aspects, including computerassisted virtual operation planning, personalized 3D printing treatment, and accurate measurement of parameters. Many previous studies also showed particular advantages of the $3 \mathrm{D}$ reconstruction technique compared with conventional methods, including more detailed and accurate preoperative information, fewer surgical complications, less blood loss, a shorter operation time, and fewer fluoroscopic images (7,8,23,29-32). However, 3D model reconstruction still requires more time and effort compared to the $1 \mathrm{D}$ or $2 \mathrm{D}$ measurement methods. Thus, simplifying the operating procedures of $3 \mathrm{D}$ measurement remains a problem to be addressed. 


\section{Conclusions}

Our results showed that an OLFV ratio of greater than $26.3 \%$ is the most valuable CT-based radiological parameter for the diagnosis of OLF-induced thoracic myelopathy, and is superior to the conventional $1 \mathrm{D}$ and $2 \mathrm{D}$ radiological parameters. The novel diagnostic method based on the OLFV ratio will help to determine the responsible segment in multi-segmental thoracic OLF or in cases of thoracic OLF coexisting with other degenerative spinal diseases. The OLFV ratio also accurately reflects the clinical state of symptomatic patients with thoracic OLF.

\section{Acknowledgments}

Funding: This study was supported by the Undergraduate Innovation Fund of Second Military Medical University (Spine Surgery Department), the National Natural Science Foundation of China (No. 81802218), and the Shanghai Science and Technology Commission Technology Support Project (No. 18441905800).

\section{Footnote}

Conflicts of Interest: All authors have completed the ICMJE uniform disclosure form (available at http://dx.doi. org/10.21037/qims-20-713). The authors have no conflicts of interest to declare.

Ethical Statement: The study was approved by Medical Ethics Committee, Shanghai Changzheng Hospital and informed consent was taken from all the patients.

Open Access Statement: This is an Open Access article distributed in accordance with the Creative Commons Attribution-NonCommercial-NoDerivs 4.0 International License (CC BY-NC-ND 4.0), which permits the noncommercial replication and distribution of the article with the strict proviso that no changes or edits are made and the original work is properly cited (including links to both the formal publication through the relevant DOI and the license). See: https://creativecommons.org/licenses/by-nc-nd/4.0/.

\section{References}

1. Gao R, Yuan W, Yang L, Shi G, Jia L. Clinical features and surgical outcomes of patients with thoracic myelopathy caused by multilevel ossification of the ligamentum flavum.
Spine J 2013;13:1032-8.

2. Ju JH, Kim SJ, Kim KH, Ryu DS, Park JY, Chin DK, Kim KS, Cho YE, Kuh SU. Clinical relation among dural adhesion, dural ossification, and dural laceration in the removal of ossification of the ligamentum flavum. Spine $\mathbf{J}$ 2018;18:747-54.

3. Moon BJ, Kuh SU, Kim S, Kim KS, Cho YE, Chin DK. Prevalence, distribution, and significance of incidental thoracic ossification of the ligamentum flavum in Korean patients with back or leg pain: MR-based cross sectional study. J Korean Neurosurg Soc 2015;58:112-8.

4. Inamasu J, Guiot BH. A review of factors predictive of surgical outcome for ossification of the ligamentum flavum of the thoracic spine. J Neurosurg Spine 2006;5:133-9.

5. Feng F, Sun C, Chen Z. A diagnostic study of thoracic myelopathy due to ossification of ligamentum flavum. Eur Spine J 2015;24:947-54.

6. Lee BJ, Park JH, Jeon SR, Rhim SC, Roh SW. Clinically significant radiographic parameter for thoracic myelopathy caused by ossification of the ligamentum flavum. Eur Spine J 2019;28:1846-54.

7. Lee N, Ji GY, Shin HC, Ha Y, Jang JW, Shin DA. Usefulness of 3-dimensional measurement of ossification of the posterior longitudinal ligament (OPLL) in patients with OPLL-induced myelopathy. Spine (Phila Pa 1976) 2015;40:1479-86.

8. Yan C, Jia HC, Xu JX, Xu T, Chen K, Sun JC, Shi JG. Computer-based 3D simulations to formulate preoperative planning of bridge crane technique for thoracic ossification of the ligamentum flavum. Med Sci Monit 2019;25:9666-78.

9. Katsumi K, Watanabe K, Izumi T, Hirano T, Ohashi M, Mizouchi T, Ito T, Endo N. Natural history of the ossification of cervical posterior longitudinal ligament: a three dimensional analysis. Int Orthop 2018;42:835-42.

10. Kim SI, Ha KY, Lee JW, Kim YH. Prevalence and related clinical factors of thoracic ossification of the ligamentum flavum-a computed tomography-based cross-sectional study. Spine J 2018;18:551-7.

11. Li WJ, Guo SG, Sun ZJ, Zhao Y. Multilevel thoracic ossification of ligamentum flavum coexisted with/without lumbar spinal stenosis: staged surgical strategy and clinical outcomes. BMC Musculoskelet Disord 2015;16:206.

12. Kasukawa $Y$, Miyakoshi N, Hongo M, Ishikawa Y, Kudo D, Kimura R, Ono Y, Li da J, Sato C, Shimada Y. Surgical results of patients with myelopathy due to ossification of the ligamentum flavum with ossification of the posterior longitudinal ligament or a vertebral fracture at the same 
level of the thoracic spine: a retrospective comparative study. Asian Spine J 2019;13:832-41.

13. Baba H, Tomita K, Kawahara N, Kikuchi Y, Imura S. Spinal cord evoked potentials in thoracic myelopathy with multisegmental vertebral involvement. Spine (Phila $\mathrm{Pa}$ 1976) 1992;17:1291-5.

14. Resnick DK, Anderson PA, Kaiser MG, Groff MW, Heary RF, Holly LT, Mummaneni PV, Ryken TC, Choudhri TF, Vresilovic EJ, Matz PG; Joint Section on Disorders of the Spine and Peripheral Nerves of the American Assosiation of Neurological Surgeons and Congress of Neurological Surgeons. Electrophysiological monitoring during surgery for cervical degenerative myelopathy and radiculopathy. J Neurosurg Spine 2009;11:245-52.

15. Li X, An B, Gao H, Zhou C, Zhao X, Ma H, Wang B, Yang H, Zhou H, Guo X, Zhu H, Qian J. Surgical results and prognostic factors following percutaneous full endoscopic posterior decompression for thoracic myelopathy caused by ossification of the ligamentum flavum. Sci Rep 2020;10:1305.

16. DeLong ER, DeLong DM, Clarke-Pearson DL. Comparing the areas under two or more correlated receiver operating characteristic curves: a nonparametric approach. Biometrics 1988;44:837-45.

17. Søreide K, Kørner H, Søreide JA. Diagnostic accuracy and receiver-operating characteristics curve analysis in surgical research and decision making. Ann Surg 2011;253:27-34.

18. Sanghvi AV, Chhabra HS, Mascarenhas AA, Mittal VK, Sangondimath GM. Thoracic myelopathy due to ossification of ligamentum flavum: a retrospective analysis of predictors of surgical outcome and factors affecting preoperative neurological status. Eur Spine J 2011;20:205-15.

19. Yoon SH, Kim WH, Chung SB, Jin YJ, Park KW, Lee JW, Chung SK, Kim KJ, Yeom JS, Jahng TA, Chung CK, Kang HS, Kim HJ. Clinical analysis of thoracic ossified ligamentum flavum without ventral compressive lesion. Eur Spine J 2011;20:216-23.

20. Kawaguchi Y, Urushisaki A, Seki S, Hori T, Asanuma Y, Kimura T. Evaluation of ossification of the posterior longitudinal ligament by three-dimensional computed tomography and magnetic resonance imaging. Spine J 2011;11:927-32.

21. Yu L, Li B, Yu Y, Li W, Qiu G, Zhao Y. The relationship between dural ossification and spinal stenosis in thoracic ossification of the ligamentum flavum. J Bone Joint Surg Am 2019;101:606-12.

22. Lee JJ, Shin DA, Yi S, Kim KN, Yoon DH, Shin HC,
Ha Y. Effect of posterior instrumented fusion on threedimensional volumetric growth of cervical ossification of the posterior longitudinal ligament: a multiple regression analysis. Spine J 2018;18:1779-86.

23. Shin DA, Ji GY, Oh CH, Kim KN, Yoon DH, Shin H. Inter- and intra-observer variability of the volume of cervical ossification of the posterior longitudinal ligament using Medical Image Processing Software. J Korean Neurosurg Soc 2017;60:441-7.

24. An SB, Lee JJ, Kim TW, Lee N, Shin DA, Yi S, Kim KN, Yoon DH, Ha Y. Evaluating the differences between 1D, $2 \mathrm{D}$, and $3 \mathrm{D}$ occupying ratios in reflecting the JOA score in cervical ossification of the posterior longitudinal ligament. Quant Imaging Med Surg 2019;9:952-9.

25. Resnick D, Niwayama G. Radiographic and pathologic features of spinal involvement in diffuse idiopathic skeletal hyperostosis (DISH). Radiology 1976;119:559-68.

26. Mader R, Verlaan JJ, Buskila D. Diffuse idiopathic skeletal hyperostosis: clinical features and pathogenic mechanisms. Nat Rev Rheumatol 2013;9:741-50.

27. Liang H, Liu G, Lu S, Chen S, Jiang D, Shi H, Fei Q. Epidemiology of ossification of the spinal ligaments and associated factors in the Chinese population: a crosssectional study of 2000 consecutive individuals. BMC Musculoskelet Disord 2019;20:253.

28. Zhang HQ, Chen LQ, Liu SH, Zhao D, Guo CF. Posterior decompression with kyphosis correction for thoracic myelopathy due to ossification of the ligamentum flavum and ossification of the posterior longitudinal ligament at the same level. J Neurosurg Spine 2010;13:116-22.

29. Burkhard JP, Dietrich AD, Jacobsen C, Roos M, Lübbers HT, Obwegeser JA. Cephalometric and three-dimensional assessment of the posterior airway space and imaging software reliability analysis before and after orthognathic surgery. J Craniomaxillofac Surg 2014;42:1428-36.

30. Sun JC, Sun KQ, Sun SX, Xu XM, Wang Y, Kong QJ, Yang HS, Guo YF, Shi GD, Shi JG. Computer-assisted virtual operation planning in anterior controllable anterior-displacement and fusion surgery for ossification of the posterior longitudinal ligament based on actual computed tomography data. Clin Neurol Neurosurg 2019;177:86-91.

31. Chen Y, Jia X, Qiang M, Zhang K, Chen S. Computerassisted virtual surgical technology versus threedimensional printing technology in preoperative planning for displaced three and four-part fractures of the proximal end of the humerus. J Bone Joint Surg Am 
2018;100:1960-8.

32. Jud L, Müller DA, Fürnstahl P, Fucentese SF, Vlachopoulos L. Joint-preserving tumour resection around the knee with allograft reconstruction using threedimensional preoperative planning and patient-specific instruments. Knee 2019;26:787-93.
Cite this article as: Yan C, Tan HY, Ji CL, Yu XW, Jia HC, Li FD, Jiang GC, Li WS, Zhou FF, Ye Z, Sun JC, Shi JG. The clinical value of three-dimensional measurement in the diagnosis of thoracic myelopathy caused by ossification of the ligamentum flavum. Quant Imaging Med Surg 2021;11(5):20402051. doi: 10.21037/qims-20-713 